\title{
Visual perception in the determination of spacecraft attitude '
}

JOSEPH PUIG, ${ }^{2}$ GRUMMAN AIRCRAFT ENGINE ERING CORPORATION ROBERT ZENHAUSERN, ST. JOHN'S UNIVERSITY

A simulation experiment was conducted in order to evaluate the effectiveness of a colored light pattern in providing cues necessary to determine spacecraft orientation. The light pattern proved effective in providing these cues.

The space rendezvous concept involves obtaining a constant-bearing intercept along which a schedule of braking can be applied. The resulting collision course produces a closure condition which terminates in the final controlled contact between the two vehicles. In Project Apollo, the two spacecraft involved in the rendezvous are the Apollo Command Module ( the "mother vehicle") and the Lunar Module (LM) which is designed to ferry two of the three astronauts from the Command Module to the lunar surface and back.

The docking phase of the LM with the Command Module on the return from the lunar surface commences at $900 \mathrm{ft}$ separation between the two vehicles. An examination of the information required at predocking separation of 900 to $200 \mathrm{ft}$ indicates that gross attitude judgment would be required at the greater distance, with finer judgments at the shorter distances in order to align the vehicles for the final docking maneuvers. The ability to proficiently close with the target is the primary consideration, with conservation of fuel and mission time as secondary factors.

Although the probability of docking under sunlight conditions is extremely high, consideration was given to a docking situation which might take place during the dark phase of the lunar orbit. In the absence of direct sunlight, other possible sources of light during the dark phase of orbit would be earthlight (sunlight reflected from the earth's surface), earthlight reflected from the moon's surface, and starlight. In the worst case, only starlight would be available to illuminate the orbiting spacecraft.

In order to safeguard against this possibility, it was decided to incorporate an exterior, color-coded lighting configuration on the LM to provide visual docking cues. Five point-source incandescent light fixtures made up the configuration.

The purpose of the present study was to determine, using simulation procedures, whether the lighting configuration of the LM provided adequate cues to spacecraft orientation.

\section{Apparatus}

The apparatus included a $1 / 32$ scale model of the Ascent Stage of the LM, painted a semigloss white and equipped with miniature colored lights scaled down in intensity to simulate actual operational conditions. The model was suspended at the center of a gimbal arrangement which permitted movement of the model about its three mutually perpendicular axes.

Figure 1 is a representation of the LM, indicating the so-called Euler angles used in this study. Yaw defines movement about the vehicle's $x$-axis; pitch defines movement about the $y$-axis; and roll defines movement about the z-axis. Depending on the view of the model, different light patterns were presented to the S: (1) front view-two horizontally arranged lights, white and yellow; (2) rear view-a single white light; (3) left view-the yellow front light, a red side light, and the white rear light; (4) right view - similar to the left side, but the light pattern was white, green, white; (5) top view-the two white lights on the front and rear; (6) bottom view-no lights were visible.

The "grain of wheat" lamps (CM8-666), manufactured by the Chicago Miniature Lamp Works, were operated at $3 \mathrm{~V}$. Silikrome silicon rubber colored filters made by APM-Hexseal Corp. were used to obtain the appropriate color coding.

\section{Subjects}

Three aircraft pilots, ranging in age from 32 to 41 years, were used as Ss. All had normal color vision and two had $20 / 20$ visual acuity without corrective lenses. One $S$ had $20 / 20$ acuity with glasses. The oldest $S$ was a former naval aviator who is still an active flyer with the Naval Reserve and Grumman Aircraft Engineering Corp. The other two Ss were former Air Force pilots presently on reserve duty with the Air National Guard.

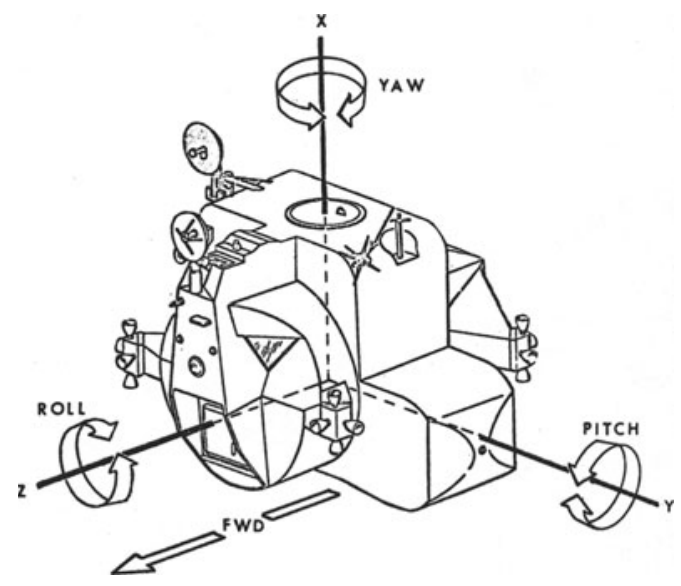

Fig. 1. Diagram of LM showing Euler angles. 


\section{Procedure}

All Ss were given preliminary practice until their performances showed adequate familiarization with the task. Indoctrination with the model, position of the lights, and the method of movement was first made with the room lights on. The lights were gradually dimmed for each practice session, until the procedure was finally conducted in the dark, with only the LM docking lights visible.

The $\mathrm{S}$ was comfortably seated behind a desk with his head at the same height as the center of the spacecraft model. A chinrest was used to position the S's head in proper relation to the model and to restrain excessive head movement during the session. A dark adaptation period of $15 \mathrm{~min}$ was used before each session.

The distances from the $S$ to $L M$ were $6.25 \mathrm{ft}$ and $28 \mathrm{ft}$, simulating the 200 and $900 \mathrm{ft}$ distances important in the actual space docking procedures. During each trial, the model was positioned to represent a different view of the LM, front, rear, sides, top, or bottom. The model was moved by hand at the rate of about $0.1 \mathrm{degree} / \mathrm{sec}$, the lower threshold for the perception of motion of a point source against a dark background (Graham, 1951). None of the Ss reported real movement during the experiment. The various combinations of two distances, six views, and three motions (yaw, pitch, and roll) were presented in randomized order. The Ss' task was to determine either alignment or misalignment from the zero degree point.

The psychophysical method of limits, using six ascending and six descending trials, was employed to determine the mean angular deviation from perfect alignment. "Blank" trials, randomly interspersed with test trials, failed to elicit "false alarms"' under any conditions.

\section{Results and Discussion}

An examination of the deviation thresholds indicated that they were well within the standards set by NASA; that is, the deviation thresholds were sufficiently small to permit the use of an exterior lighting configuration as an aid to pre-docking alignment. The thresholds ranged from a low of .81 degrees for pitch motion in a top view at $6.25 \mathrm{ft}$ to a high of 14.70 degrees for pitch motion in a bottom view at $28 \mathrm{ft}$. The mean threshold at $6.25 \mathrm{ft}$ was approximately 3 degrees and at $28 \mathrm{ft}$, approximately 4 degrees.

A three way analysis of variance with main effects distance, views, and motion was calculated for each S. As could be expected, detection of misalignment was more difficult at the $28 \mathrm{ft}$ distance. The mean pitch thresholds were highest (5.42 degrees), but there were no significant differences between yaw and roll $(3.50$ and 3.54 degrees, respectively). Due to the geometric structure of the LM, there were differential view effects. Front, rear, and bottom views (mean deviations: 5.74 degrees) were significantly more difficult to align than left, right, and top views (mean deviations: 3.08 degrees). There were no significant differences within this dichotomous breakdown. In all cases, however, the deviation thresholds were sufficiently small to allow adequate pre-docking alignment.

Examination of $S$ differences indicated a wide range of ability to utilize the perceptual cues. The $S$ with the lowest thresholds under all conditions was a Navy pilot who had had considerable experience in carrier landings at night. Possibly, this type of experience provides positive transfer for pre-docking alignment under conditions of low illumination.

\section{Reference}

Graham, C. H. Visual perception. In S. S. Stevens (Ed.), Handbook of experimental psychology. New York: John Wiley \& Sons, Inc., 1951. Pp. 868-920.

\section{Notes}

1. This study was performed at Grumman Aircraft Engineering Corporation under Contract NAS 9-1100 to the Manned Spacecraft Center, National Aeronautics and Space Administration, Houston, Texas.

2. This study was submitted in partial fulfillment of the requirements for the degree of Master of Arts at St. John's University by Mr. Puig. 